Supplement of Clim. Past, 13, 395-410, 2017

http://www.clim-past.net/13/395/2017/

doi:10.5194/cp-13-395-2017-supplement

(C) Author(s) 2017. CC Attribution 3.0 License.

(c) (1)

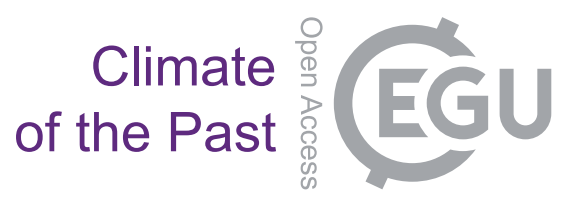

Supplement of

\title{
Aromatic acids in a Eurasian Arctic ice core: a 2600-year proxy record of biomass burning
}

Mackenzie M. Grieman et al.

Correspondence to: Mackenzie M. Grieman (mgrieman@uci.edu)

The copyright of individual parts of the supplement might differ from the CC-BY 3.0 licence. 
Table 1: Tie points based on pollution and volcanic eruptions used for the Akademii Nauk ice core depthage scale (Arienzo et al., 2016; Sigl et al., 2013, 2015).

\begin{tabular}{llll}
\hline Tie point & Year $(\mathrm{CE})$ & Depth $(\mathrm{m})$ & Signal \\
\hline pollution & 1955 & 25.96 & lead, plutonium, vanadium \\
Katmai & 1912 & 52.12 & sulphur \\
Laki & 1783 & 104.93 & sulphur \\
unknown eruption 1 & 1594 & 168.16 & sulphur \\
Bárðarbunga & 1477 & 209.18 & sulphur, thallium, cadmium \\
unknown eruption 2 & 1330 & 258.46 & sulphur \\
Samalas & 1258 & 281.26 & sulphur \\
unknown eruption 3 & 1231 & 289.22 & sulphur \\
Katla & 1179 & 304.15 & sulphur, cadmium \\
unknown eruption 4 & 1169 & 306.02 & sulphur \\
unknown eruption 5 & 743 & 406.78 & sulphur, thallium \\
\hline
\end{tabular}
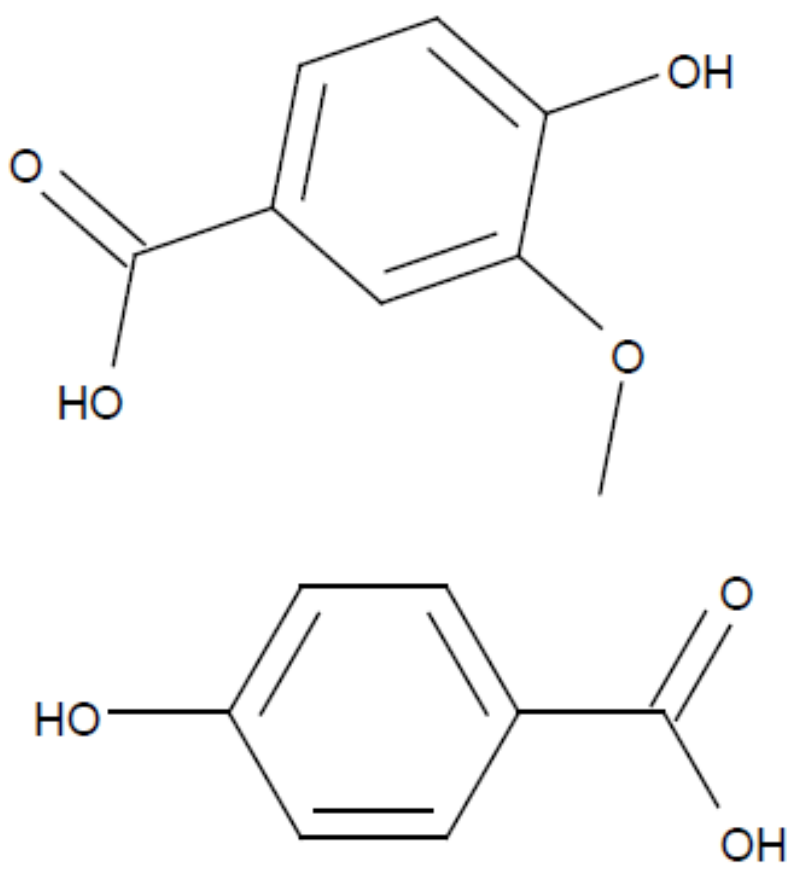

Figure 1: Molecular structures of vanillic acid $\left(\mathrm{C}_{8} \mathrm{H}_{8} \mathrm{O}_{4}\right.$; top) and para-hydroxybenzoic acid $\left(\mathrm{C}_{7} \mathrm{H}_{6} \mathrm{O}_{3}\right.$; bottom). 


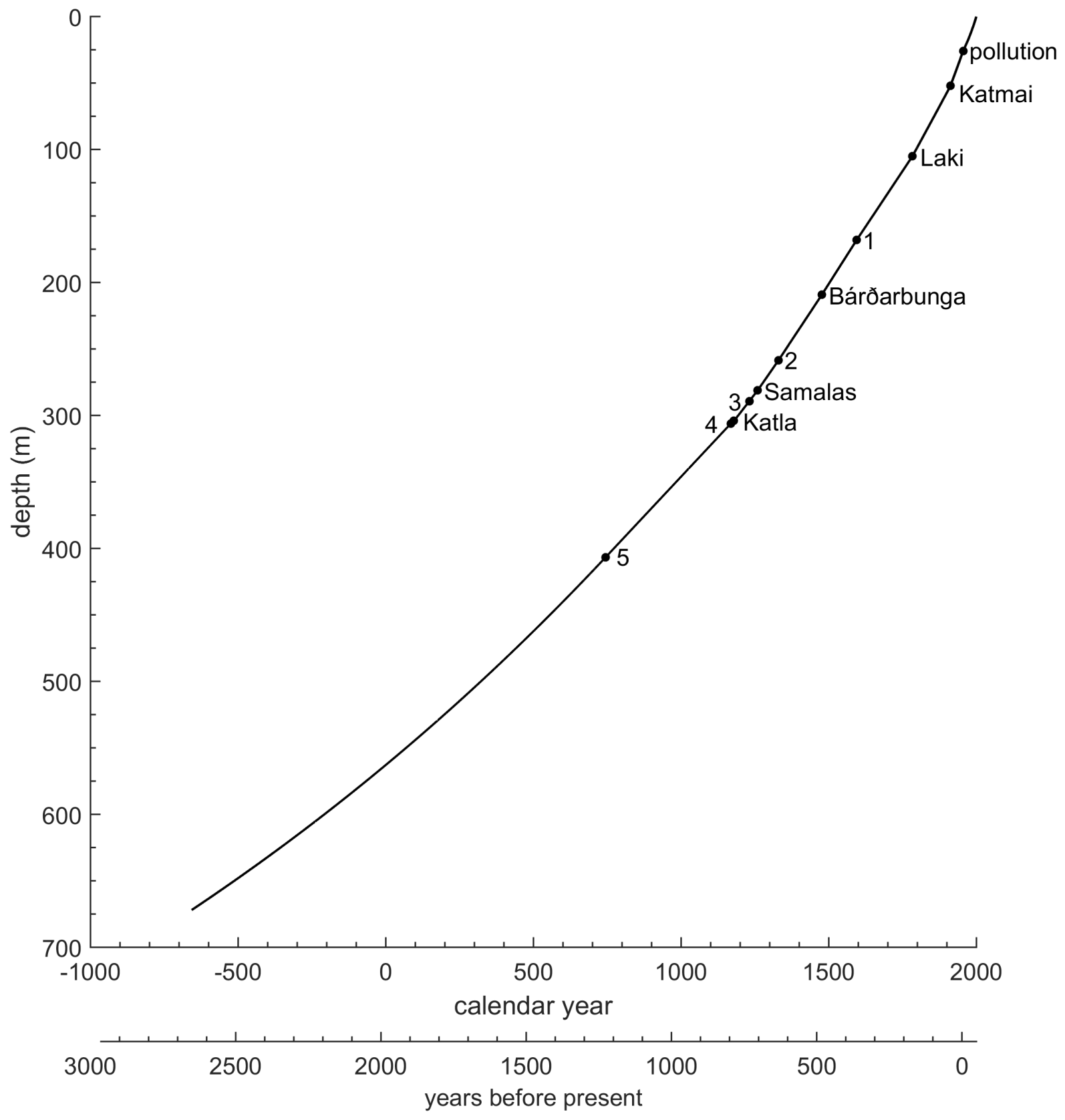

Figure 2: Akademii Nauk ice core depth-age scale. The dating is based on identification of common events (e.g., volcanic signatures) in other Arctic ice cores (see for example Sigl et al., 2015) on the NEEM-2011S1 timescale (Sigl et al., 2013). A continuous age scale was developed by linear interpolation between tie points and a linear decreasing annual layer thickness below the deepest tie point (743 CE). Points are the tie points. Numbers are tie points that are volcanic eruptions of unknown origin. 

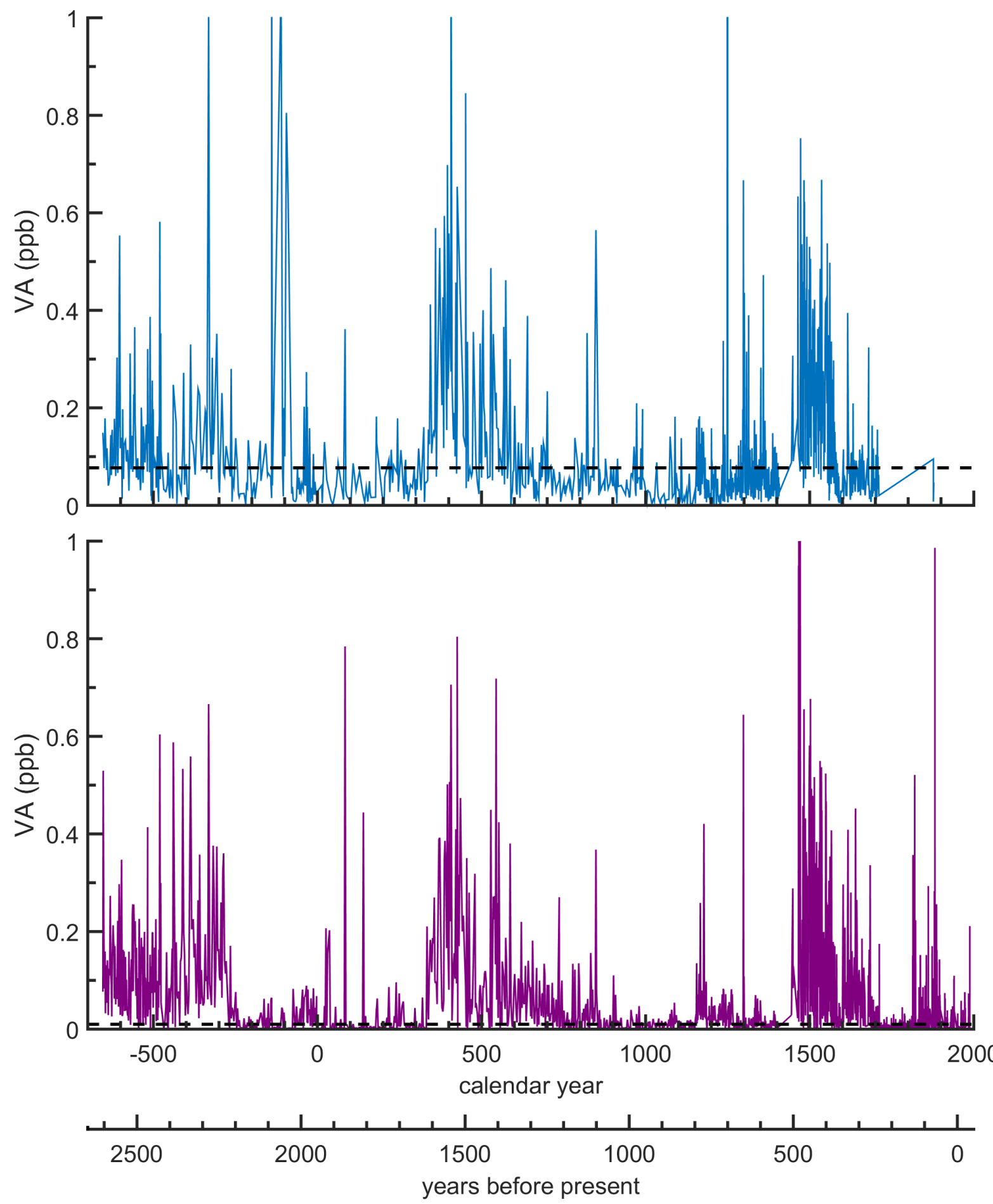

Figure 3: Akademii Nauk vanillic acid ice core measurements using two different analytical techniques. Top - High performance liquid chromatography with electrospray ionization and tandem mass spectrometry (HPLC-ESI/MS/MS); Bottom - Ion chromatography with electrospray ionization and tandem mass spectrometry (IC-ESI/MS/MS). Dotted horizontal lines are the limits of detection. Similar results were obtained by both techniques. IC-ESI/MS/MS has a significantly lower detection limit and improved quantitation over HPLC-ESI/MS/MS. 

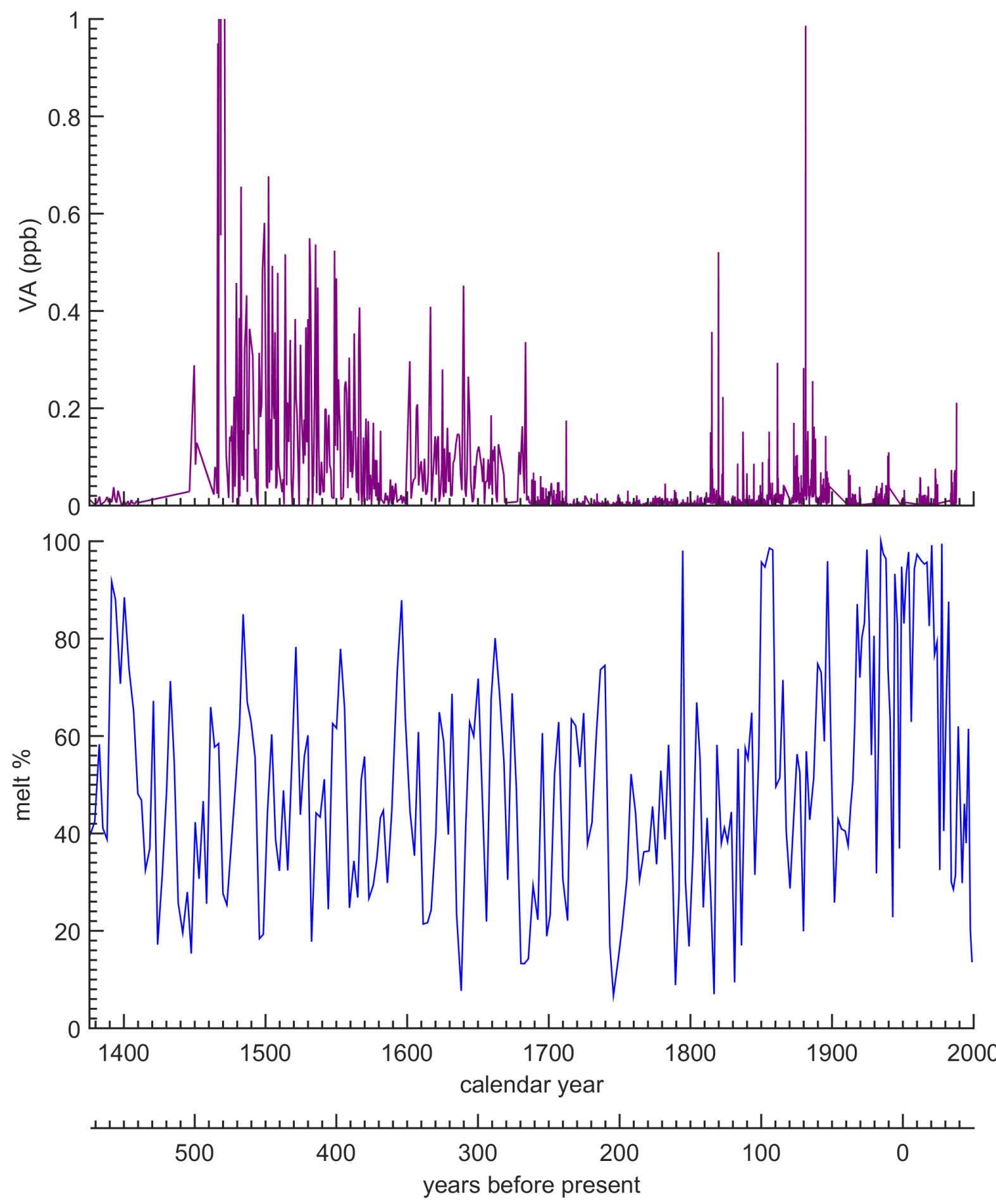

Figure 4: Akademii Nauk vanillic acid (top) and the distribution of melt layers in the ice core (bottom). Melt layer percentage is defined as the amount of melt layer ice in each meter of ice by weight (Fritzsche et al., 2005). 

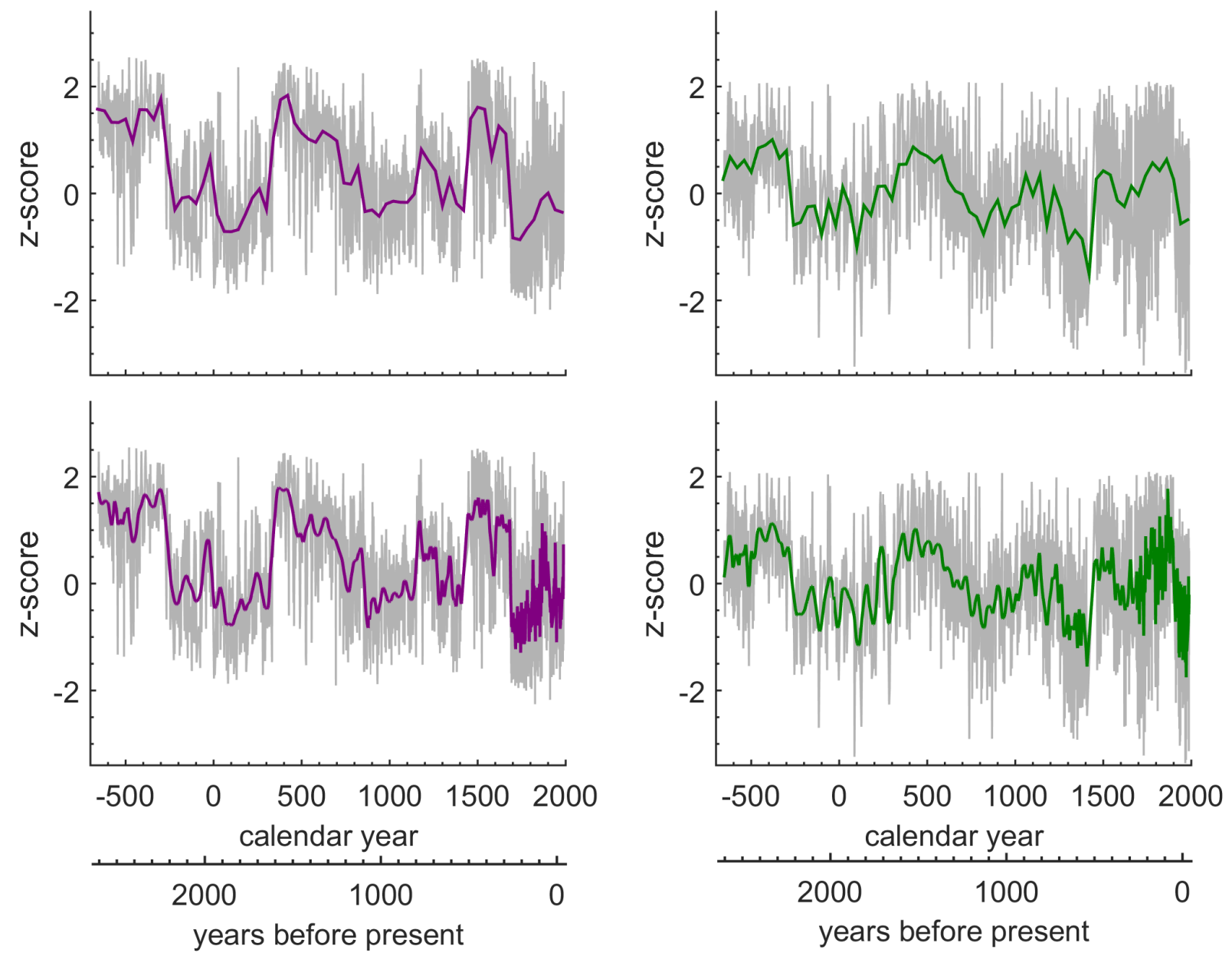

Figure 5: Akademii Nauk vanillic acid (left) and para-hydroxybenzoic acid (right) using 40-year bin averaging (top) and LOESS smoothing (span $=0.013$ ) (bottom). Outliers were omitted prior to analyses. Data were normalized using the log transformation, mini-max transformation, and the z-score (grey lines). LOESS is a smoothing method using locally weighted polynomial regression (LOESS; Cleveland and Devlin, 1988). 

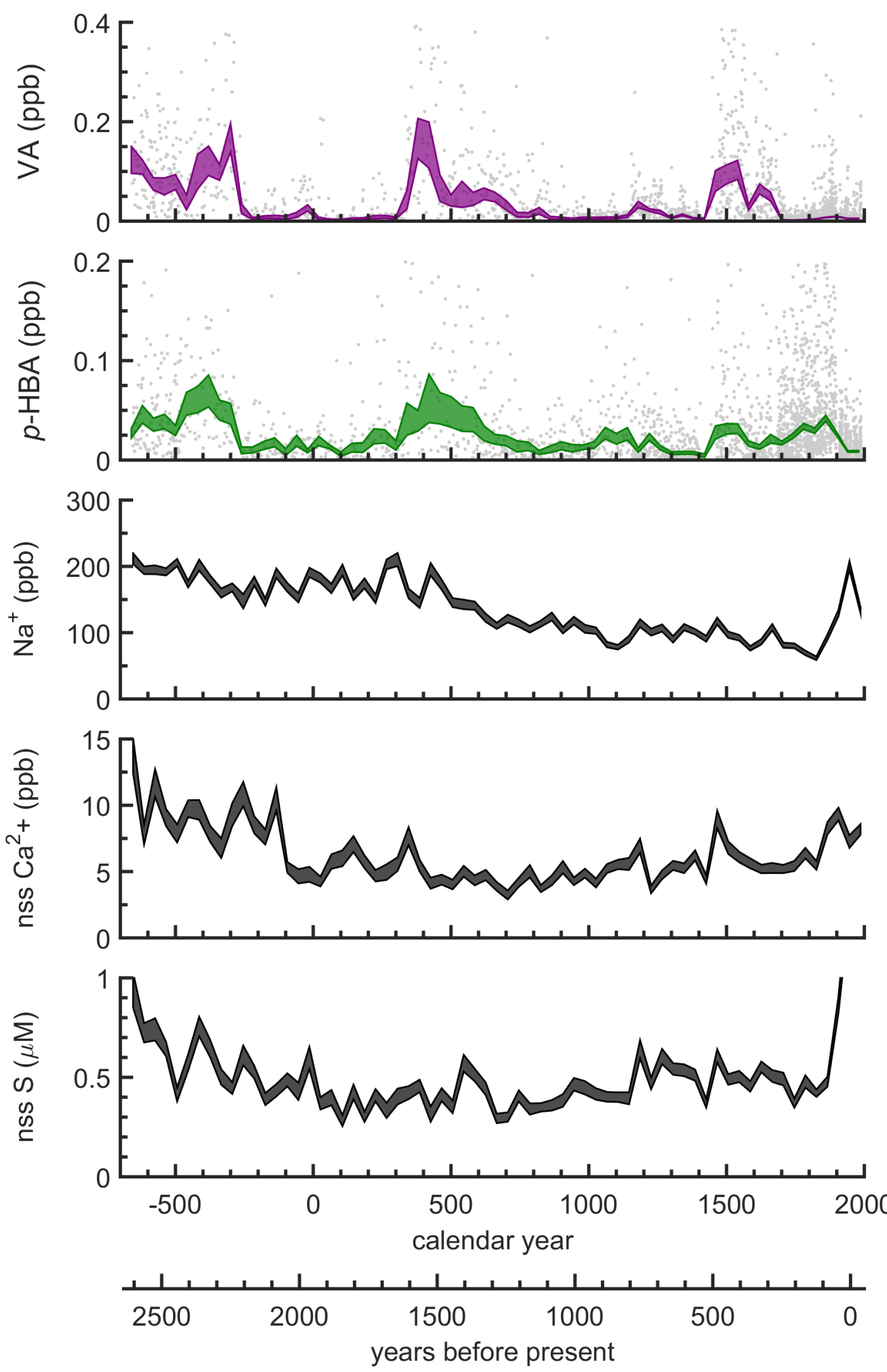

Figure 6: Akademii Nauk ice core chemistry over the past 3,000 years. Data are 40-year bin-averaged (fills are \pm 1 standard error of log transform) measurements. From top: 1) VA measurements, 2) p-HBA measurements, 3) sodium, 4) non-sea salt calcium, and 5) non-sea salt sulphur. 


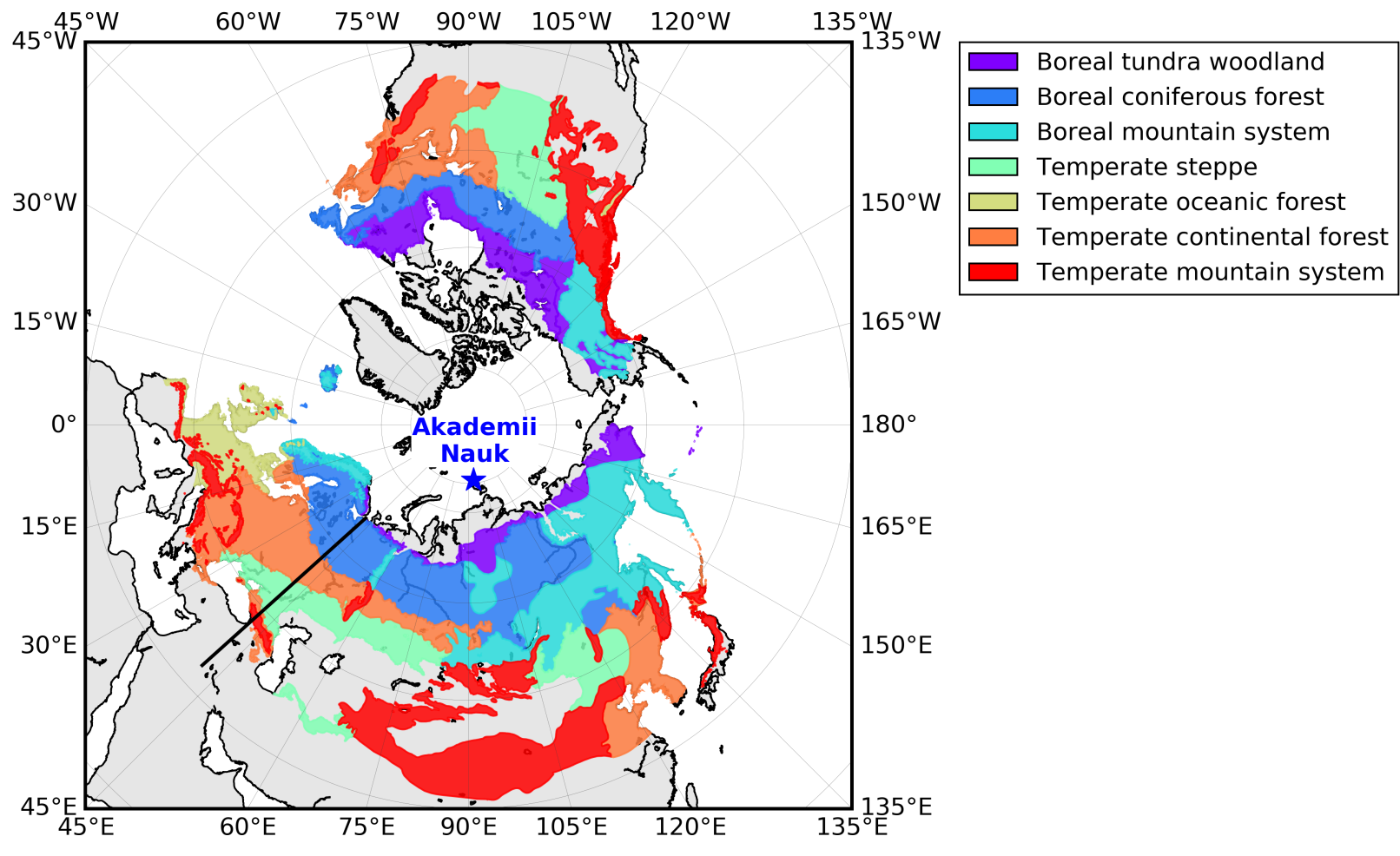

Figure 7: Map of ecofloristic zones defined by the Food and Agriculture Organization (Ruesch and Gibbs, 2008). The black line defines the boundary $\left(42^{\circ} \mathrm{E}\right)$ between Siberia and Europe used for HYSPLIT trajectory analysis. 


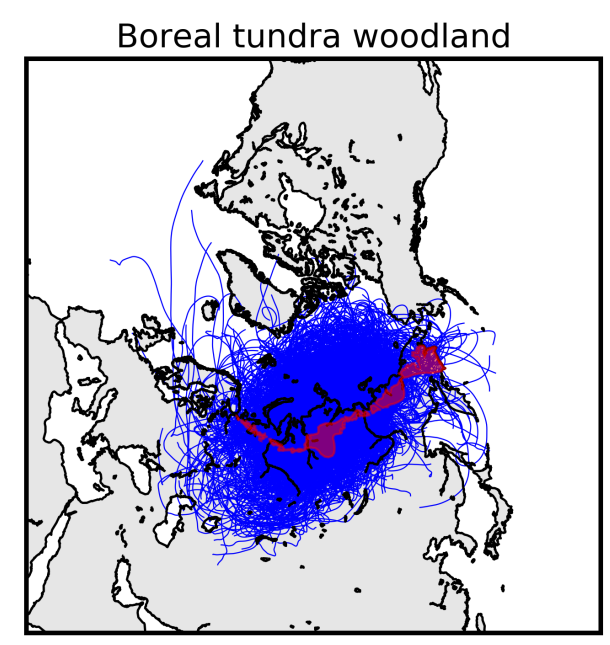

Boreal mountain system

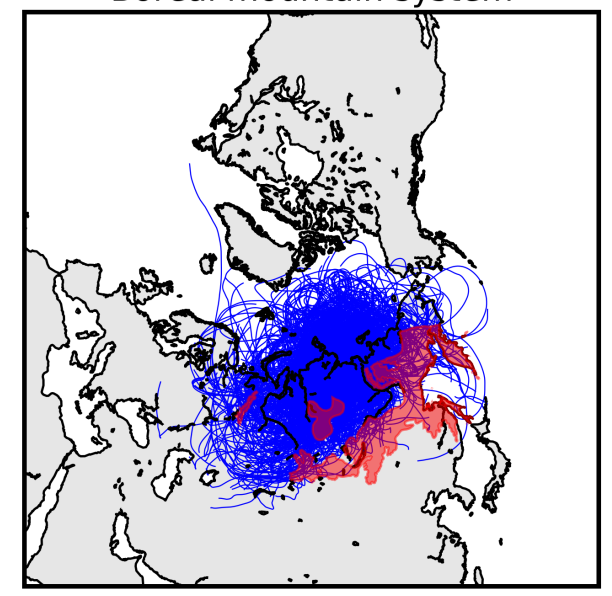

Temperate continental forest

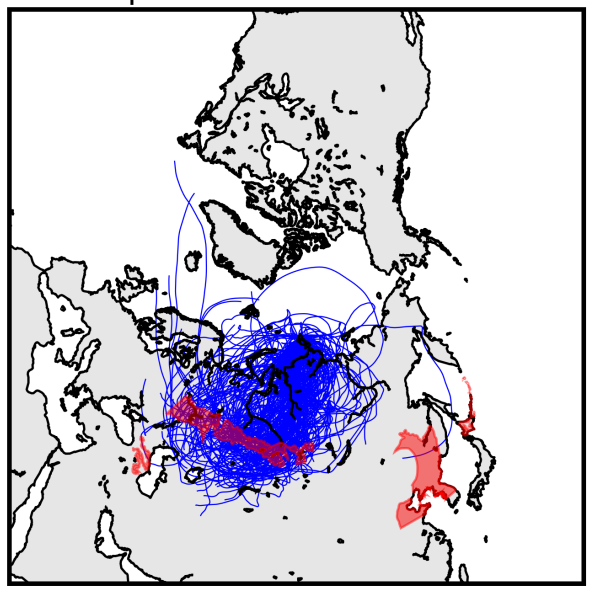

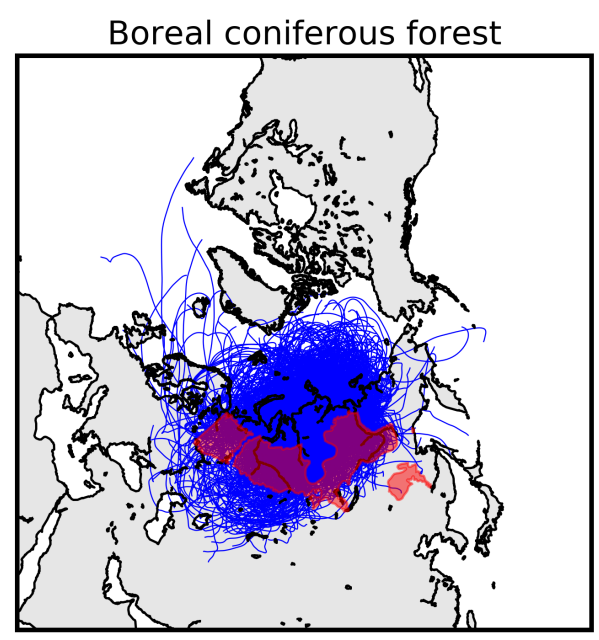

Temperate steppe

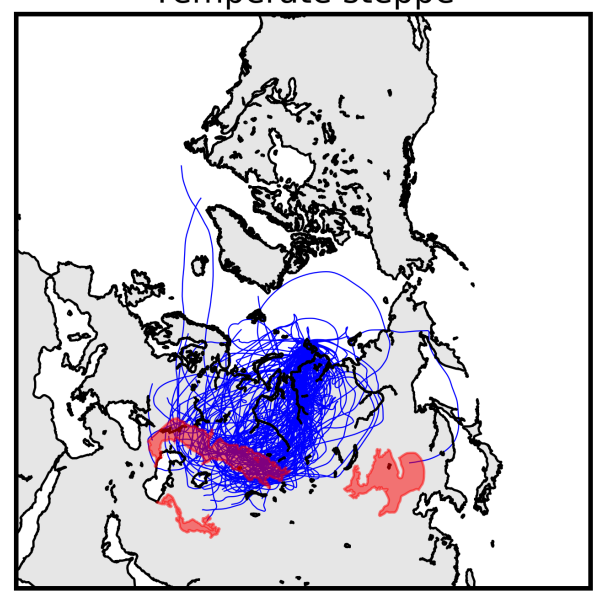

Temperate mountain system

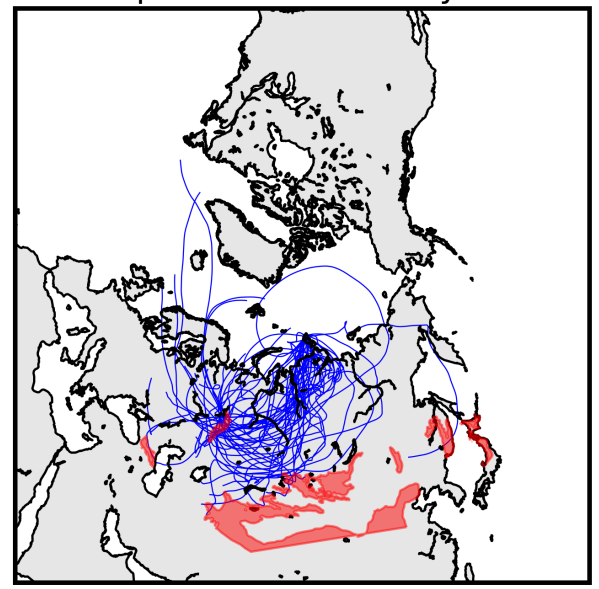

Figure 8: Maps of 10-day air mass back-trajectories using the HYSPLIT model from the Akademii Nauk ice core site. All back trajectories start at 12:00 AM and 12:00 PM from $100 \mathrm{~m}$ above ground level for the years 2006-2015 CE. Blue lines are trajectories from spring, summer, and fall (March 1-November 30) that transect or originate from each of the Siberian ecofloristic zones. Siberia is defined as landmass east of $42^{\circ} \mathrm{E}$. The ecofloristic zones (red) are defined by the Food and Agriculture Organization (Ruesch and Gibbs, 2008). Left panel from top: 1) Boreal tundra woodland, 2) Boreal mountain system, and 3) Temperate continental forest. Right panel from top: 1) Boreal coniferous forest, 2) Temperate steppe, and 3) Temperate mountain system. 


\section{References}

Arienzo, M. M., McConnell, J. R., Chellman, N., Criscitiello, A. S., Curran, M., Fritzsche, D., Kipfstuhl, S., Mulvaney, R., Nolan, M., Opel, T., Sigl, M., and Steffensen, J.: A Method for Continuous 239Pu Determinations in Arctic and Antarctic Ice Cores, Environmental Science \& Technology, 50, 7066-7073, doi:10.1021/acs.est.6b01108, 2016.

Cleveland, W. S. and Devlin, S. J.: Locally Weighted Regression: An Approach to Regression Analysis by Local Fitting, Journal of the American Statistical Association, 83, 596-610, doi:10.1080/01621459.1988. 10478639, 1988.

Fritzsche, D., Schütt, R., Meyer, H., Miller, H., Wilhelms, F., Opel, T., and Savatyugin, L. M.: A 275 year ice core record from Akademii Nauk ice cap, Severnaya Zemlya, Russian Arctic, Annals of Glaciology, 42, 361-366, doi:10.3189/172756405781812862, 2005.

Ruesch, A. and Gibbs, H. K.: New IPCC Tier-1 global biomass carbon map for the year 2000, Carbon Dioxide Information Analysis Center, Oak Ridge National Laboratory, 2008.

Sigl, M., McConnell, J. R., Layman, L., Maselli, O., McGwire, K., Pasteris, D., Dahl-Jensen, D., Steffensen, J. P., Vinther, B., Edwards, R., Mulvaney, R., and Kipfstuhl, S.: A new bipolar ice core record of volcanism from WAIS Divide and NEEM and implications for climate forcing of the last 2000 years, Journal of Geophysical Research: Atmospheres, 118, 1151-1169, doi:10.1029/2012JD018603, 2013.

Sigl, M., Winstrup, M., McConnell, J., Welten, K., Plunkett, G., Ludlow, F., Büntgen, U., Caffee, M., Chellman, N., Dahl-Jensen, D., et al.: Timing and climate forcing of volcanic eruptions for the past 2,500 years, Nature, 523, 543-549, doi:10.1038/nature14565, 2015. 